\title{
Psychological Challenges of Women in Maiduguri Metropolis Internally Displaced Persons' Camp: Counselling Implications
}

\author{
Hamsatu Joseph. Pur $\mathrm{PhD}^{1^{*}} \quad$ Iya Haruna Ayuba $\mathrm{PhD}^{2} \quad$ Beatrice Chinonso Maduagwu $\mathrm{PhD}^{1}$ \\ 1. Department of Education, University of Maiduguri, Nigeria \\ 2. Unit of Guidance and Counselling, Department of Educational Foundations, Nasarawa State university, Keffi, \\ Nigeria
}

\begin{abstract}
The study determined the psychological challenges of women in Maiduguri Internally Displaced Persons' camp and its implication for counselling. Three objectives guided the study. With a descriptive survey design, the population of the study comprised 1,100 internally displaced women from Wulari IDP camp located within Maiduguri Metropolis, Borno State. This study utilized non probability convenient sampling technique to get the sample for the study. Data for the study were collected from 100 willing internally displaced women through an instrument titled "Psychological Challenges Identification Questionnaire (PCIQ)" designed by the researchers. Test-retest reliability method utilized for the instrument provided a reliability coefficient of 0.85 using the Pearson Product Moment Correlation. The data collected were analysed using descriptive statistics of mean, standard deviation, frequency count and percentage. The findings of the study revealed that the leading sources of psychological trauma among IDP women were prolonged stay in camp, loss of loved ones, threats constituted by Boko Haram in the camp and abandonment by the government. It was further revealed that $61 \%$ of the respondents are psychologically challenged with living in constant fear, constant nightmares, feeling depressed and insomnia as major psychological challenges experienced by these women. Based on the findings of the study, it was concluded that women were psychologically challenged as a result of insurgency attack. Hence, it was recommended that professional counsellors and psychologists should be deployed to all the IDP camps in the state to assist the women overcome their psychological challenges and live a fulfilled life.
\end{abstract}

Keywords: Psychological Challenges, Internally Displaced Women, Internally Displaced Person's Camp.

DOI: $10.7176 / \mathrm{JCSD} / 56-06$

Publication date: February $29^{\text {th }} 2020$

\section{Introduction}

Conflicts arising from the activities of Boko Haram have been a threat to lives and properties, where death casualties have been recorded and many people have been displaced (Rushing, 2014). Globally, reports from Office for the Coordination of Humanitarian Affairs (2015) stated that over 40 million people were displaced as a result of wars and violence rooted in religious and ethnic conflicts in 2015, with19.2 million people displaced by natural disasters such as famine and floods. In Africa, 12 million people were displaced by armed conflict and violence and there were hundreds of thousands of people displaced by natural disasters. Conflicts and disasters often cause large scale displacement of people especially when destruction of homes and environment occur.

Internally displaced persons (IDPs) are persons or groups of people who have been forced or obliged to flee or leave their homes and places of habitation as a result of or in order to avoid the effects of armed conflicts, situations of generalized violence, violations of human rights, natural or man-made disasters, who have not crossed an internationally recognized state border (Office for the Coordination of Humanitarian Affairs $\{$ OCHA\}, 1999). Owoaje (2016) pointed that global estimates indicating the number of people displaced annually by conflict and violence has increased since 2003. An average of 5.2 million people for instance, has been displaced annually in the past 13 years due to insurgency, political instability and terrorist activities of groups such as ISIS and Boko Haram particularly in the Middle East and Sub-Saharan Africa (Owoaje, 2016).

Women and children constitute more than 50 percent of internally displaced camps formation (Internal Displacement Monitoring Centre Report $\{I D M C\}, 2016)$. IDP population composed of 53 percent women and 47 percent males. Displaced women are often at greater risk than other affected population. They face many challenges such as loss of livelihoods, health care, lack of proper sanitation and educational services needed for daily life (IDMC, 2012). These women tend to have less access to assistance and struggle to have access to adequate education, health care, training and means of livelihoods. In consonance, Adimola (2016) reported that internally displaced women lack health care facilities in IDP camps. The displaced women are unable to regain pre-conflict way of living because of their poor conditions of living with rigors of long journeys, safety challenges, harassment, frequent sexual abuse, child molestation, forced labor, and poor sanitation. All these challenges causes psychological trauma in women.

Due to these challenges, Internally Displaced Women (IDW) are more susceptible to Sexual and GenderBased Violence (SGBV), they face difficulties in exercising their rights to housing, land, and property. They are also often excluded from decision-making processes. These human rights violations are compounded by conflict, 
which exacerbates pre-crisis patterns of discrimination. Age group affiliation (e.g. membership in minority groups), disability, civil status, socio-economic status and displacement all place internally displaced women at great risk of being psychologically traumatized (Project on Internal Displacement, 2014).

Human Rights Watch (2014) stated that the rise in the activities of Boko Haram has brought about adverse effect on the North-Eastern population especially on women and children which is evident in the increased number of widows and orphans in Borno, Yobe and Adamawa States. Displaced women are more likely to be socially isolated and lack traditional protective mechanisms. Their increased economic vulnerabilities place them at a higher risk of prostitution and forced marriages. Also, women who lost their husbands to conflict face additional challenges and responsibilities as heads of household. Gender and sexual based violence have been on the increase due to the incessant and increased activities of the insurgence since 2009 which left many women psychologically traumatised. It was revealed that women have been raped and sexually exploited as a result of conflict with Boko Haram. Human right watch (2014) also observed that government is not doing enough to protect displaced women, by way ofensuring that they have access to basic rights and services or to sanction the abusers, among which include camp leaders, vigilante groups, policemen and soldiers, as well as displaced men counterparts living within the IDP camps.

In late July, 2016, Human Rights Watch documented sexual abuse, including rape and exploitation, of 43 women and girls living in seven internally displaced persons (IDP) camps in Maiduguri, the Borno State capital. The victims had been displaced from different local government areas of Borno state. According to Mausi Segun, senior Nigeria researcher at Human Rights Watch (2014), "it is bad enough that these women are not getting much-needed support for the horrific trauma they suffered at the hands of Boko Haram". He further lamented that people who should protect these women and girls are attacking and abusing them. Four of the victims told Human Rights Watch that they were drugged and raped, while 37 were coerced into sex through false marriage promises and material and financial assistance. Many of those coerced into sex said they were abandoned when they became pregnant. They and their children have suffered discrimination, abuse and stigmatization from other camp residents. In addition, eight of the victims alleged that they were previously abducted by Boko Haram fighters and forced into marriage before they escaped to Maiduguri (IDMC, 2014). Gender and sexual based violence are believed to be widespread phenomenon among internally displaced women in various Internally Displaced Persons' (IDP) campsand in host communities which predisposes them to psychological challenges.

Based on the Diagnostic and Statistical Manual of Mental Disorders (DSM-5), Kendra (2018) identified the following psychological challenges; loss of appetite, anxiety (persistent fear), loss of sleep, lack of interest in activities previously enjoyed, delirium (confusion), constant feeling of sickness, easily irritated, constant worry, crying always, suicidal thoughts, feeling of isolation, depression, mood shifts, constant flashes of distressing memories of the crisis, difficulty in experiencing positive emotions, hopelessness, constant outburst of anger, nightmares, difficulty in concentrating, inability to remember people/events among others. While it is good to determine the psychological challenges that internally displaced women experience, it is equally paramount to come up with counselling approaches through which the sources of the challenges would be managed, curtailed and possibly discontinued, so that every counselling remedy to the psychological well-being of the women in question would be meaningful and effective.

\section{Statement of the Problem}

Displacement has different effects on women than it has on men and differs during various stages of crises. When displacement occurs, far more damage results than simply the loss and destruction of goods and properties. People's lives and the social fabric are left in attars. As terrible as the disruption may be, women usually suffer the effects acutely than men do. Changes in gender roles are accelerated in situations of conflict as women are forced to assume responsibilities previously held by men.

The rights of women, including access to food, and basic services such as water supply, shelter, and health care are often ignored. Moreover, displaced women have no voice; their circumstances compel them to accept the little assistance offered while being denied the opportunity to actively participate in program design, monitoring or assessments on activities that directly affect their lives and their children. Women interviewed by the researchers in the Maiduguri camps confided that to survive; they had to be nice to the soldiers guarding the camp. Sexual assault, for example, has become a prominent consequence of highly concentrated IDP camps. In addition, UNHCR (2015) reported that efforts to protect IDP women have been largely unsuccessful, with humanitarian workers often being unfamiliar with guidelines meant to safeguard women facing rape and sexual violence. The researchers also observed that concern for menstrual sanitary materials is often overlooked entirely in IDP camps, as it does not fall into the primary needs of refugees for most aid agencies.

Child marriage has been an issue throughout the last ten years of displacement. Families unable to care for all the members of their families sometimes resort to marrying off their female children to men who are often much older for both protection and economic security in IDP camps. The emotional struggles of these children leave women with psychological wound. In an attempt to bring about counselling intervention to the 
psychological challenges of these women, this study therefore determined the psychological challenges of women in Maiduguri Internally Displace Persons camps, Borno state with the following objectives:

1. To determine the sources of psychological challenges among women in Maiduguri internally displaced persons' camp

2. To find out the psychological challenges prevalent among women in Maiduguri internally displaced persons' camp

3. To determine the percentage of Internally Displaced women who are psychologically challenged?

\section{Research Questions}

1. What are the sources of psychological challenges among women in Maiduguri internally displaced persons' camp?

2. What are the psychological challenges being faced by Internally Displaced Women in IDP camps?

3. What percentage of Internally Displaced women is psychologically challenged?

\section{Methodology}

The study adopted descriptive survey design to determine psychological challenges of women in Maiduguri Internally Displaced Persons' Camp. Oche (2007) define survey design as one in which a group of people is studied by collecting and analysing data through the use of such instrument as questionnaire from only a few people considered to be a representative sample of the entire population. The population of the study comprised 1,653 internally displaced women from Wulari IDP camp located within Maiduguri Metropolis, Borno State. This study utilized non probability convenient sampling technique to get the sample for the study. One hundred volunteers and willing internally displaced women gave their consent to participate in the study. Majority of women seemed not to appreciate and understand the rationale for the study as they felt it would compromise their security. In view of this challenge, the researchers employed a non-probability sampling method.

The instrument for data collection was a questionnaire design by the researchers which gave in-depth narrative on ground situation from the minds of respondent. The instrument titled "Psychological Challenges Identification Questionnaire (PCIQ)" was divided into two sections (A and B). Section A sought for respondents' personal data while Section B consisted two clusters: Part A and Part B. Part A contained 14 items on sources of psychological challenges among women in IDP camps while Part B comprised 15 items on the psychological challenges among internally displaced women in the camp. The instrument was a four point Likert scale (Strongly Agree (SA) - 4, Agree (A) - 3, Disagree (D) - 2, Strongly Disagree (SD) - 1) with 60 as the maximum score and 0 , the minimum score for Part B on the psychological challenges among internally displaced women. Ranked scores are as follows; 0 to 15 indicated very low psychological challenges, 16 to 30 signified moderate psychological challenges, 31 to 45 implied high psychological challenges and 46 to 60 connoted very high psychological challenges.

The instrument was validated by some experts in the measurement and evaluation unit from the department of Vocational Education, University of Maiduguri. The researchers applied test-retest technique for determining reliability of the instrument using a sample of 30 respondents in Bakassi IDP camp. By this, the researchers were able to determine the clarity of items, identified any ambiguity in the items, and determined the reliability index of the instrument. The retest was within 2 weeks interval and using Pearson's Correlation, a reliability coefficient of 0.85 was realised which shows that the instrument was reliable.

Prior to the time for data collection, the researchers obtained a letter of permission from State Emergency Management Agency to enable them visit the camp. The camp officials were informed about the topic and the purpose of the research. With permission of these relevant authorities, the researchers gained access into the camp, introduced themselves to the IDP women, and gave willing participants informed consent forms. The consent form contained information on the purpose, protocols, benefits of the study and an assurance that the information obtained would be confidential and strictly for research purposes. After willing participants had signed the forms, the researchers administered the questionnaire and retrieved them immediately after completion. The data collected were analysed using descriptive statistics of mean, standard deviation, frequency count and percentage.

\section{Results}

Research Question 1: What are the major sources of psychological challenges among women in Maiduguri internally displaced persons' camp? 
Table 1: Descriptive Analysis on Sources of Psychological Challenges of IDP Women in Maiduguri Metropolis

\begin{tabular}{|c|c|c|}
\hline Items & $\bar{X}$ & SD \\
\hline Fellow displaced persons are a threat to me & 2.10 & 1.124 \\
\hline The presence of security agents has been the most depressing & 1.88 & 1.148 \\
\hline Boko Haram threatens us even in Camp & 3.18 & 0.730 \\
\hline I have been sexually harassed/assaulted by unknown persons & 2.45 & 0.978 \\
\hline We feel abandoned by the government & 3.14 & 0.766 \\
\hline I hardly see food to eat every day & 2.96 & 0.887 \\
\hline My past pleasant memories make me sad & 2.09 & 0.854 \\
\hline I have been sexually harassed/assaulted by the security men in the camp & 1.84 & 0.907 \\
\hline I am troubled about the prolonged stay in camp & 3.25 & 0.770 \\
\hline The killing of my loved ones depresses me & 3.22 & 0.786 \\
\hline It is impossible to find rest in camp & 3.10 & 0.861 \\
\hline Catering for my children troubles me & 2.64 & 1.115 \\
\hline I am always denied of my rights in the camp since the death of my husband & 2.15 & 1.086 \\
\hline $\begin{array}{l}\text { I don't have access to sanitary pads, clean water, and toilet facilities during } \\
\text { menstruation }\end{array}$ & 2.82 & 1.218 \\
\hline Total & 36.85 & 6.455 \\
\hline
\end{tabular}

$\boldsymbol{N}=$ number of subjects $; \overline{\mathbf{X}}=$ mean $; \boldsymbol{S D}=$ standard deviation

Table 1 reveals the major sources of psychological challenges among internally displaced women in Maiduguri Metropolis. The leading source is prolonged stay in camp, followed by the loss of loved ones. Threats constituted by Boko Haram in the camp is the third source while abandonment by the government, no rest in camp and scarcity of food are some of the sources of psychological challenges indicated by respondents.

Research Question 2: What are the major psychological challenges being faced by Internally Displaced Women in camps?

Table 2: Descriptive Analysis on Psychological Challenges of Women in IDP

\begin{tabular}{|l|c|c|}
\hline \multicolumn{1}{|c|}{ Items } & $\bar{X}$ & SD \\
\hline I always feel depressed & 3.00 & 0.804 \\
\hline Life is not worth living anymore hence, I often feel like committing suicide & 2.56 & 1.008 \\
\hline I have loss of appetite & 2.90 & 0.948 \\
\hline I live in constant fear & 3.49 & 0.689 \\
\hline I have problems with sleep & 2.99 & 0.835 \\
\hline I lack interest in activities I previously enjoyed & 2.95 & 0.968 \\
\hline I am always confused & 2.94 & 0.827 \\
\hline I always feel sick & 2.83 & 0.897 \\
\hline I find it difficult to express positive emotions like joy, laughter & 3.00 & 0.876 \\
\hline I have lost all hope & 2.40 & 1.989 \\
\hline I express unnecessary outburst of anger & 2.96 & 0.931 \\
\hline I have constant nightmares & 3.34 & 0.714 \\
\hline I find it difficult to concentrate & 2.96 & 0.887 \\
\hline I can hardly remember people/events & 2.88 & 0.967 \\
\hline I always like to be alone & 2.73 & 1.118 \\
\hline Total & 43.93 & 7.846 \\
\hline
\end{tabular}

$\boldsymbol{N}=$ number of subjects $; \overline{\boldsymbol{X}}=$ mean $; \boldsymbol{S D}=$ standard deviation

Table 2 presents the major psychological challenges being faced by internally displaced women. The results reveal that living in constant fear is the main psychological challenge faced by the IDP women. It further reveals that constant nightmares, feeling depressed, difficulty in expressing positive emotions and insomnia are also some of the psychological challenges.

Research Question 3: What percentage of Internally Displaced women is psychologically challenged? 
Table 3: Percentage of Psychologically Challenged Internally Displaced Women

\begin{tabular}{|l|l|l|l|l|}
\hline Level & Score & Interpretation & $\mathbf{N}$ & $\mathbf{\%}$ \\
\hline Low & $0-15$ & Manageable & 0 & 00.0 \\
\hline Moderate & $16-30$ & Less healthy & 0 & 00.0 \\
\hline High & $31-45$ & Threatening & 61 & 61.0 \\
\hline Very High & $46-60$ & Unhealthy & 39 & 39.0 \\
\hline Total & & & 100 & $100.0 \%$ \\
\hline
\end{tabular}

$N=$ number of subjects; $\%=$ percent

Table 3 shows that $61 \%$ of the respondents are psychologically challenged at a level considered to be high and threatening to their psychological well-being. Quite worrisome however, $39 \%$ of the respondents are already experiencing very high and completely unhealthy psychological challenges that require urgent attention.

\section{Discussions}

Results of the study in relation to the major sources of psychological challenges among internally displaced women in Maiduguri Metropolis revealed that the leading source of psychological challenges among IDP women include: prolonged stay in camp, the loss of loved ones, threats constituted by Boko Haram in the camp, abandonment by the government, lack of rest in camp and scarcity of food among others. This is in conformity with the findings of Human Right Watch (2014) which established that the government is not doing enough to protect displaced women to ensure that they have access to basic rights and services, or to sanction the abusers, who include camp leaders, vigilante groups, policemen and soldiers.

The study further revealed that the major psychological challenges being faced by internally displaced women are: living in constant fear, constant nightmares, feeling depressed, difficulty in expressing positive emotions and insomnia among others. This is quite worrisome. Perhaps this is reason Adimola (2016) stressed that displaced women are unable to regain pre-conflict way of living because of their poor conditions of living with rigors of long journeys, safety challenges, and harassment, frequent sexual abuse, child molestation, forced labour and poor sanitation. All these challenges cause psychological trauma in women.

The findings also revealed that about $61 \%$ of the respondents were psychologically challenged at a level considered to be high and threatening to their psychological well-being. Quite bothersome is the finding which reported that $39 \%$ of the respondents were already experiencing very high and completely unhealthy psychological challenges that require urgent attention. This finding is in line with the position of Human Rights Watch (2014) which reported that internally displaced women are not getting the much-needed support for the horrific trauma they suffered at the hands of Boko Haram. Hence, intensified efforts must be made to help these women overcome this life threatening situation.

\section{Implications for counselling}

The findings of this study have implications for counselling since displaced women struggle with psychological challenges due to traumatic experiences from insurgency attack. First, the prolonged stay of women in IDP camp, loss of loved ones and incessant attacks constitute major sources of psychological challenges for them. Counsellors and psychologists have the requisite knowledge to understand how devastating it can be for the women hence, they can advocate on behalf of the IDPs to relevant authorities on the need to urgently relocate them from camps to government allotted houses. The advocacy can be in form of peaceful protest; it can also be through advocacy on mass media in the interest of IDPs.

Secondly, it is informative to counsellors and psychologists that women in IPDs live in constant fear hence professional counsellors and psychologists can synergize and design counselling intervention programs that can regularly be delivered to these women in order to ensure emotional stability.

Similarly, reports revealed that IDP women are psychologically challenged at a level considered to be high and threatening to their psychological well-being. There is therefore need to engage professional counsellors and psychologists to help internally displaced women to realize their potentials in order to overcome and develop the philosophy that will enable them to live a happy life despite the life threatening condition they have found themselves.

\section{Conclusion}

Based on the findings of this study, it was concluded that the displaced women have been struggling with psychological challenges due to their traumatic experience as a result of insurgency attacks. It was also concluded that the displaced women are psychologically challenged at a level considered to be high and threatening to their psychological well-being. Hence, concerted efforts must be made by the government of Nigeria and non- governmental organizations to cushion the effects of the Boko Haram insurgency on displaced women. 


\section{Recommendations}

Based on the findings of the study, the researchers recommended that the state government should ensure that internally displaced women feel safe and have a sense of belonging by relocating them to different housing estates built by state government. This will help in minimizing the psychological effects of the insurgency attack on them.

It is important for government officials to increase the frequency of their visits to IDP camps. This will increase the quantity of materials given to victims in the camp. Weekly visits for instance, will ensure proper distribution of materials and will also ensure that counsellors, psychologists, government agencies and humanitarian bodies be prompt at addressing rising concerns among women.

Also, the government and humanitarian organizations in the state should make concerted efforts to ensure that these displaced women are protected from molestation and attacks in the camps as well as have access to basic rights and services. Professional counsellors and psychologists should also be deployed to all the IDP camps across the state to rehabilitate those psychologically affected by the insurgency attack in order to help them overcome their psychological challenges and live a fulfilled life.

\section{References}

Adimola, B. (2018). Integrating internally displaced women and children in peace process speech at the international women's day March 8, Abuja

Human Right Watch (2014). Internally Displaced People: A global survey in NorthernNigeria Retrievedfrom http://www.hrw.org/en/reports/2013/05/20/IDP.NEN.

Internal Displacement Monitoring Centre Report (2016).Global over view. Retrieved from http://www.internaldisplacement.org/publications/globaloverview.

Internal Displaced Monitoring Centre (2012). Global overview of internally displaced person by hazard-induced Geneva; National Commission for refugees (NCFR)

Internal Displaced Monitoring Centre (2016).Global report on internal displacement: Retrieved from http://www.internal-displacement.org/publications/globaloverview

Kendra, C. (2018). A list of psychological disorders. Retrieved from www.verywellmind.com

Office for the Coordination of Humanitarian Affairs (OCHA, 1999). Briefing packs and Humanitarian Action Plans, Midyear Review and final report, United Nations.

Owoaje, E. T. (2016) A review of health problems of the internally displaced persons in Africa. Journal of Nigerian Postgrad

Rusihing, E. J. (2014). Nigeria: Multiple displacement,crises overshadowed by Boko Haram. Regional analysis for West Africa. Retrieved from http://www.internal-displacement.org
UNHCR
(2015).
Global
trend
2015.
Retrieved
from http.//www.unhcr.org/news/latest/2015/6/5763b65a4/global-force-displacement-hits-record-high.hml. 